\title{
Comparing the organization of public research funding in central and eastern European countries
}

\author{
Benedetto Lepori, Jaan Masso, Julita Jabłecka, \\ Karel Sima and Kadri Ukrainski
}

\begin{abstract}
In this article, we present a comparative analysis of the organization of public funding of research in three central and eastern European countries. We first compare the organization of funding agencies, the portfolio of funding instruments and, finally, the repartition of funding by beneficiaries. Further, we identify the main structural characteristics of the funding systems, by looking at features like sectoral divisions, level of delegation and the role of different institutional levels in the management of funding. Against a widespread conception of research policies in central and eastern European countries converging towards a western-style model, our study displays profound differences between the considered countries, related to history but also to contextual factors in the reform phase.
\end{abstract}

$\mathrm{D}$ URING AND AFTER the breakdown of the Communist regimes, research policies and research funding systems in central and eastern European countries (CEECs) underwent a process of restructuring (Radosevic and Auriol, 1998; Meske, 2004). This included the breakdown of the old system of governance, accompanied by a strong reduction of the investments in the sector especially at the beginning of the 1990s. Thus, under the Communist regimes, CEECs had a higher level of R\&D expenditures than expected from their level of economic development. This is no longer true and

\footnotetext{
Benedetto Lepori (corresponding author) is at the Centre for Organizational Research, Faculty of Economics, University of Lugano, via Lambertenghi 10a, 6904 Lugano, Switzerland; Email: blepori@unisi.ch. Jaan Masso and Kadri Ukrainski are at the Faculty of Economics and Business Administration, University of Tartu, Narva Rd. 4-110, Tartu, 51009, Estonia; Emails: jaan.masso@mtk.ut.ee; kadri.ukrainski@mtk.ut.ee. Julita Jabłecka is at the Centre for Science Policy and Higher Education, University of Warsaw, Str. Nowy Swiat 69, 00-046 Warsaw, Poland; Email: j.jablecka@uw.edu.pl. Karel Sima is at the Centre for Higher Education Studies, u Dvou srpu 2024/2, Praha 5 - Smichov, 150 00, Czech Republic; Email: karel. sima@centrum.cz.
}

some countries, such as Poland, even 15 to 20 years after the transition, are below this level (Radosevic, 2005). Further major changes have taken place in the organization of research systems, with dramatic decreases of industrial research expenditures and, in the public sector, the emergence of higher education institutions (HEIs) as a relevant research actor, as well as a decreasing role or even the transformation of the academies of sciences structures. Finally, we witnessed the set-up of new governance arrangements and the creation of new funding mechanisms and agencies, including instruments for funding research in higher education and the introduction of project funding instruments.

However, available evidence shows that, first, this process is far from being complete and many reforms are planned in the next years and, second, that there are large differences between individual countries in the pace of the transformation; some of them are engaged in the last phase of transformation (as are Czech Republic and Poland), some lag behind (as do Bulgaria and Romania) (Meske, 2004). Thus, the model where CEECs move from the Communist system towards a 'western' style organization of research policy might have represented rather well the first phases of transition, where the 
Benedetto Lepori obtained his degree in mathematical physics at the University of Rome in 1988 and a PhD in communication sciences at the University of Lugano in 2004 with a thesis on the Swiss research policy. He is head of the research unit on management and performance of higher education and research institutions in the Faculty of Economics of the University of Lugano, where he also teaches research policy and grant proposal writing. His research interests cover the broad domain of S\&T indicators, with a focus on indicators on public funding and on higher education institutions, comparative studies of research funding and studies of steering and governance of higher education. $\mathrm{He}$ is currently involved on different research projects and contracts at the European level, including the higher education program of the European Science Foundation, various contracts and studies financed by the European Commission and the ERAWATCH research observatory.

Jaan Masso received his $\mathrm{PhD}$ in economics in 2005. He currently works at the Faculty of Economics and Business Administration at the University of Tartu, Estonia, as a senior researcher. The list of his research areas include labour economics (labour demand, job flows, scientific workforce, firm demographics), foreign direct investments (impact on employment and productivity), and science, technology and innovation indicators (measurement of innovations, innovation impact on productivity, scientific workforce, public research funding). He has during recent years published in journals such as Eastern European Economics, Economics of Transition, Applied Economics Quarterly, European Journal of Industrial Relations and Baltic Journal of Economics.

Julita Jabłecka is a research fellow at the Centre of Science Policy and Higher Education, University of Warsaw. She received her PhD in economics and her habilitation degree in management science from University of Warsaw. In 1984 she was in the USA as a Fulbright Fellow and in 1990 was an advisor to the first post-Communist Polish Government responsible for the preparation of new science policy institutions and funding instruments. She has been a member of the Committee of Science Studies at the Polish Academy of Sciences since 1990 and its deputy chairman since 2007. She has been involved in many national and international projects. Her major interests are science and higher education policy, management and structures, peer review and the role of universities in knowledge-based economy.

Karel Sima gained an MA in history in 2002 and has been working in Centre for Higher Education Studies in Prague since July 2006 as a junior researcher. His research interests comprise higher education systems in transition countries, knowledge society and R\&D funding. He has participated in several international projects on governance in higher education, funding of research activities and processing of statistical data on higher education. At national level, he has worked as an expert for several Czech higher education institutions.

Kadri Ukrainski received her $\mathrm{PhD}$ in 2008 and has been a researcher at the Faculty of Economics and Business Administration at the University of Tartu, Estonia, since 2004. Her main research focus is related to innovation and respective policy more broadly. She has conducted research in knowledge economics, with particular emphasis on knowledge as a source of innovation; sectoral innovation systems with the focus on low- and medium-technology industries; but also science and innovation policy.

most evident specificities of Communist research policies have been removed, but a more differentiated approach, taking into account also national specificities, is now required.

This article, which is based on a project realized in the PRIME Network of Excellence on research and innovation policies, provides an in-depth analysis of public research funding systems in three central and eastern European countries - namely, Czech Republic, Estonia and Poland - matching qualitative description of funding instruments with quantitative data on the share of instruments and of their beneficiaries. The main goal is to compare the structures of public funding systems and the interplay between funding channels. This includes the degree of segmentation in domains (e.g. between academies of sciences and HEIs), the level of competition and complementarity between instruments and the role of institutional levels (the state vs. funding agencies vs. research organizations vs. research units). Further, by matching this structural analysis with data on funding volumes, we aim to understand the evolution of the system, looking also to gradual shifts in addition to radical restructuring.

The topic is of interest for comparative research policy studies, where the issue of convergence and differences between national systems has been highly debated (Lepori et al, 2007a; Senker et al, 1999). CEECs represent an ideal laboratory to study the evolution of research funding, since changes are more rapid and profound than in western European countries and there is evidence of large differences between individual countries. Moreover, the topic is also relevant for European and national research policy; data on innovation, economic performance and labour productivity are a source of concern, since according to some studies many CEECs are not performing as well in this respect as would be expected from their current level of R\&D investment (Stephan, 2002). Besides other factors, this might also be related to weaknesses in the transfer of research activities towards economic innovation ( $\mathrm{Ra}$ dosevic, 2005). While the organization of public research funding is only one of the elements to be considered, a detailed understanding of its organization might well provide some useful insights to explain this productivity gap.

The rest of the article is organized as follows. In the second section, we introduce a framework for the analysis of public research funding. The third section provides an analysis of the main components of the funding system in Czech Republic, Estonia and Poland, while the fourth section takes stock of this information to analyse the organizational structures of public funding systems in these countries. The last section proposes some general conclusions and reflections.

\section{Conceptualizing the organization of public funding systems}

Public funding systems for research have been examined in the literature from different perspectives. Some studies looked to the prevailing policy goals and intervention rationales and how they are translated in specific funding instruments (as well as their 
evolution across time; Potì and Reale, 2007); a related perspective deals with more basic features like the design of science policy (Guston, 2000) and the delegation modes underlying funding mechanisms (Braun, 2003). Detailed analyses have also been devoted to funding agencies (Braun, 1998; Van der Meulen, 2003), as well as to the strategic choices and behaviour of large performers (Sanz-Menéndez and Cruz-Castro, 2003) and of individual researchers (Laudel, 2006).

In comparative studies, these approaches have led to results concerning similarities and differences between countries. While, looking mostly to western European countries, convergence has been demonstrated concerning policy rationales (Lemola, 2002) and, to a large extent, also evaluation mechanisms (Larédo, 2008), stronger national specificities have been identified in the organization of funding agencies and instruments, which seems to be driven by their embeddedness into national systems (Senker $e t$ al, 1999; Braun et al, 2003).

This article focuses on the comparison of organizational structures of public funding of research and, specifically, on the identification of its macro-level structures. We basically represent public funding systems as a set of exchange relationships between different types of funding agencies — including ministries, research councils, other agencies - and a (usually larger) set of research performers, where the former finance performers provide research services. These relationships are highly institutionalized in form of hierarchical structures - for example, grouping research units in larger organizations such as universities - as well as funding instruments and allocation criteria; nevertheless, they leave (variable) room for individual behaviour through negotiation between funders and performers, competitive allocation with specific selection procedures and strategies of performers in fund-raising.

Beyond the micro-level dynamics, we are looking for stable configurations which characterize a large portion of the whole funding system. This includes the organization of funding agencies and instruments, looking for example for distinctions between categories of agencies, as well as types of instruments (core vs. project funding; Lepori et al, 2007a); it includes also specifying the role of different organizational levels for managing funding streams, between for example university directions and research units.

However, the most relevant issue is to identify stable arrangements in the relationships between funding agencies and performers. By this, we mean a set composed by (one or more) funding agencies, a set of allocation instruments and of performers, accounting for a significant share of public funding of research. Some of these sets might be formalized in public law and formal organizational structures, as in the case of a public research organization funding its own laboratories on its core budget, while others might be institutionalized through softer mechanisms such as past experience, joint expectations, specific competences and reputation of performers defining a stable relationship between the funder and performers side (White, 2002, on institutionalized markets).

There are some good reasons why this approach might yield interesting results. First, system-level studies of whole funding systems are relatively rare in the literature. Most studies in the field focus on individual funding schemes and agencies, with a focus on research councils (Van der Meulen, 2003; Slipersaeter et al, 2007), or on specific funding instruments, like recent work on public project funding (Lepori et al, 2007a). Looking to the main structural features might provide hints on some categorization of national systems towards the identification of some basic models and a categorization of funding systems (see Whitley, 2003).

Second, it has been argued that organizational forms of public funding have a relevant impact on the functioning of the research system and on the type of research which is supported, beyond the original policy goals and the selection mechanisms adopted (Larédo, 2008; Whitley, 2003). The idea that institutions and organizational structures matter for the development of science is not new, but it has rarely been applied to the analysis of funding systems. It might thus be that differences in performance between research systems, for example between the USA and Europe or between CEECs and western Europe, are not so much related to different policies, but to their underlying institutional and organizational structures (Bonaccorsi, 2007).

Third, available empirical evidence shows that it is exactly at the level of institutional settings and organizational structures that differences between countries remain more important, and that there is evidence of influence of national contexts, as well as of path-dependency (Senker et al, 1999; Lepori et al, 2007a). Thus, the analysis of organizational structures is a relevant entry point to understand the impact of national cultures and histories on research policies and systems. Moreover, if organizations matter for systems performance, it becomes critical to better understand their embeddedness in national contexts in order to design reform policies which are compatible with each of them, but at the same time lead to international competitiveness in science (see Amable, 2000, on social systems of innovation and production).

\section{Organizational models of public funding: three main cases}

We introduce in this section three organizational models for public funding which, in most countries, constitute the main building blocks of the whole system (Lepori et al, 2007).

Core funding to public research organizations In this mode, the state allocates a global budget to 


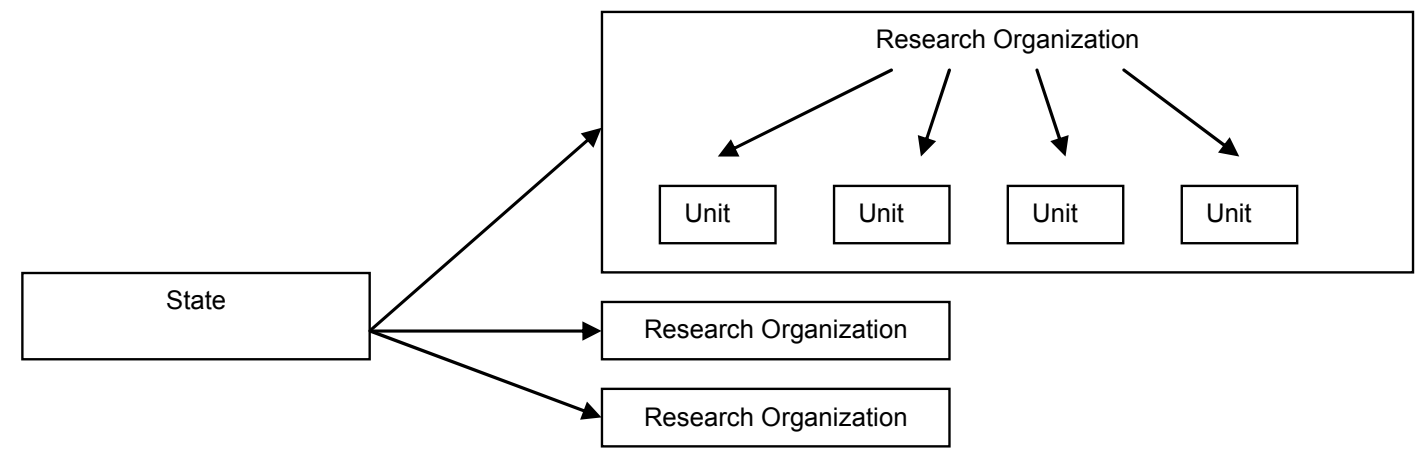

Figure 1. Funding arrangements: institutional funding

research organizations, such as universities or large public research organizations, for their normal functioning. Funding is attributed to ensure the existence of the organization and, in principle, is not limited in time; also, it is usually left to the steering body of the organization to decide how to allocate funds internally to individual units (earmarking might be present, but is typically limited to a low share of funding).

This mode creates a nested structure (Braun, 2003), with the possibility of competition both at the institutional level and at the level of internal units (Figure 1).

The organization of funding agencies, the number of players and the organization of performers can vary widely. Usually, funding of HEIs is assumed by a single ministry at national level and thus, at least in principle, there is potential competition between individual institutions; however, their number varies from country to country and this is likely to influence actor's behaviour (e.g. the likelihood of collusion between performers). In public research organizations (PROs), different settings are also possible, for example with all PROs being funded through the same agency — such as a research ministry - or with sectoral ministries funding directly their own units. In the first case, there might be direct competition for resources, in the second, competition will be between policy domains.

Moreover, there are different options concerning the allocation criteria to individual institutions, choosing between historical allocation, contractual arrangements, indicators-based allocation (see Jongbloed, 2008, for HEIs), with different degrees of competition between institutions. Also, organizational settings strongly differ concerning mission and tasks - especially between universities, where research is closely related to education and public laboratories - as well as concerning internal organizational rules and the degree of competition between internal units (Larédo, 2008).

Project funding In this mode, funding is allocated directly to a research group or an individual by a funding agency (Figure 2). The state controls the repartition of funds between agencies and instruments - the definition of the portfolio - and to some extent the allocation criteria, while it has little control on the selection of beneficiaries (Lepori et al, 2007a).

While there are a large number of studies based on the principal-agent framework on individual funding agencies (Braun, 1998; Van der Meulen, 2003), recent work has compared the structure of project funding in western European countries, showing that in almost all countries it is highly differentiated with many agencies and instruments covering most of the themes and types of research and with limited coordination (Lepori et al, 2007a); this creates room for strategic choice of the research units on how to get funded, thus reducing steering capacity of the state. However, there is some evidence that the market is segmented according to subject domains, type of research and performers; quantitative data show wide differences in the share of funding instruments attributed to different performers' categories (Lepori et al, 2007a), as well as in success rates between groups of applicants (Viner et al, 2006).

Vertical integration In this mode, a umbrella organization with a generic research mandate is delegated by the state and attributed a global budget which is then allocated to its internal units either as

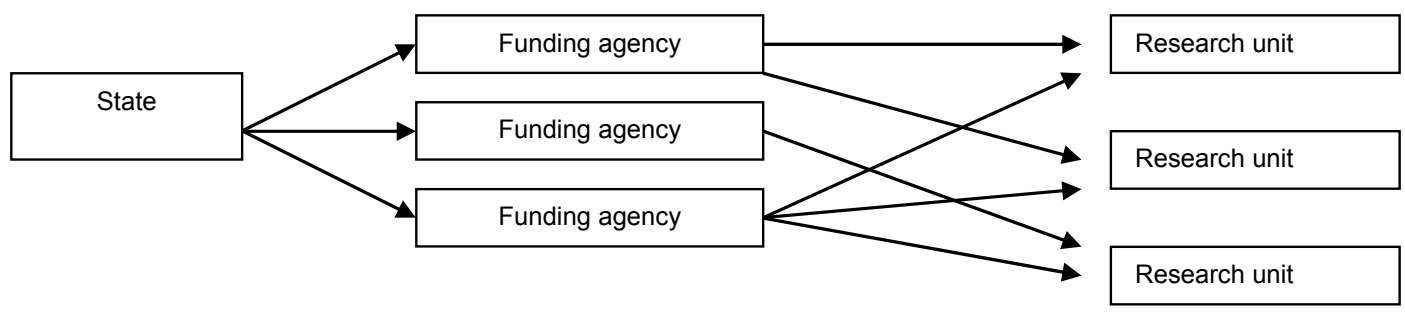

Figure 2. Funding arrangements: project funding 
institutional funding or using competitive means (Figure 3). Examples are the French National Centre for Scientific Research (CNRS) (Thèves et al, 2007), CSIC in Spain, Max-Planck Gesellschaft in Germany and the academies of sciences organizations in many CEECs before the transition.

While for some aspects this mode resembles core funding of HEIs, it shows also distinct features: thus, competition is not between umbrella organizations, being in many cases unique, but with other sectors and mechanisms, such as funding of higher education or project funding. Moreover, the umbrella organization has a larger role than funding laboratories, such as defining strategies, creating and dissolving units and setting rules for employment and internal careers; allocation of funding thus usually comes with the definition of internal evaluation mechanisms, with different settings in each case (Larédo, 2008). In fact, this mode tends to create a largely closed system with limited interaction with the rest of the research system, even if in some cases this has changed in the recent years (see Thèves et $a l, 2007$ for the case of the French CNRS). The degree of closeness/openness of these vertically integrated systems is a relevant empirical question.

\section{From individual models to a system approach}

In most countries, funding systems are composed of a combination of these models, with different proportions. One can distinguish between the US system based on project funding and the continental European one, built on a combination of core and project funding (Lepori et al, 2007a). While in some cases different modes coexist, such as core funding of HEIs alongside a vertically integrated organization such as Max-Planck Gesellschaft in Germany, in other cases they complement each other, with research units having a dual funding system based on core funding from their parent organization plus project funding from different agencies.

Our hypothesis is thus that, beyond the description of individual schemes, it is their combination that determines the characteristics of a national system, such as the capacity of the state to steer research through funding, the degree of autonomy of laboratories and the power of different organizational levels - for example, university directions vs. head of laboratories; this configuration largely determines the incentive system for performers and the conditions of their competition, inside but also across institutional sectors.

While it is by no means an aim of this article to build a complete typology of funding systems and to explore in general the relationship between its configuration and these general characteristics, we perform an exploratory analysis in the case of the three CEECs considered and inquire whether it provides some additional evidence on the system's functionality.

We perform the analysis in two steps. First, we analyse separately the three components of a funding system, namely the structure of funding bodies and the share of public funding managed by them, the types of funding instruments and their allocation criteria and, finally, the categories of research performers and their share in public research funding, as well as the share of instruments in their total resources.

In the second step, we use this information to reconstruct for the most recent years (2005 or 2006) the structural scheme of public funding, as well as for an overall characterization and comparison between the three involved countries.

The chosen perimeter includes public research funding, attributed by national states and international agencies and programmes such as the European Union. To certain extent also funding from private charities has been included, as it is by its goals rather similar to public research funding. We include to some extent public funding to private companies, but no complete analysis of private research funding is provided. For the sake of simplicity, we include only research funding to HEI, excluding funding for educational activities (with the exception of funding to $\mathrm{PhD}$ students, considered as research funding). This is a very rough approximation since research and education in universities are difficult to separate; however, the situation in CEECs is partially different since at their origin HEIs were not supposed to do research.

Information and data have been collected for each of the three countries by the project participants, using official reports and state budgets or directly from the funding agencies. Time coverage is in most cases from the mid-1990s to 2005-2006.

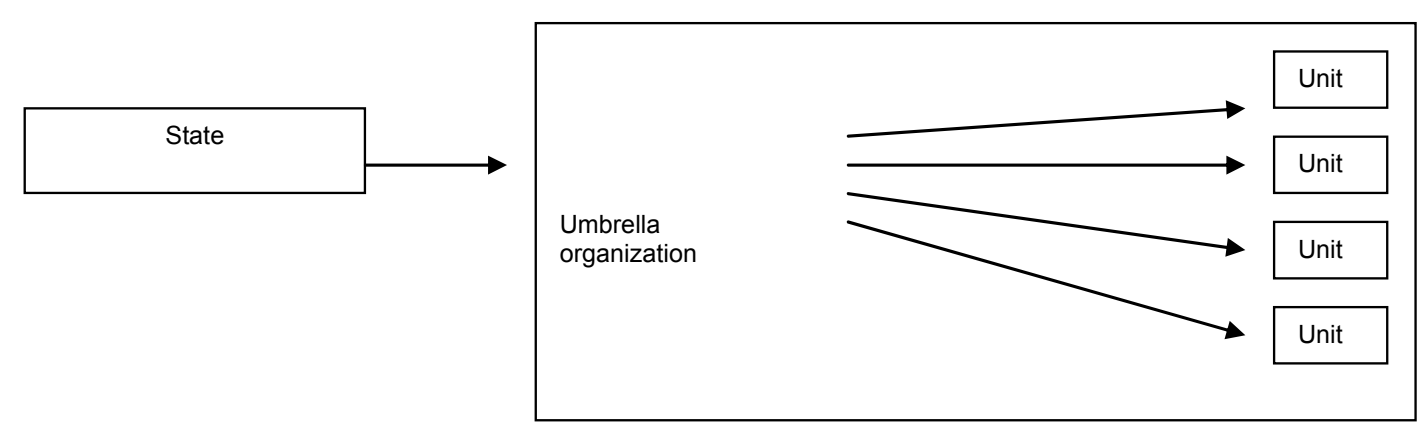

Figure 3. Funding arrangements: vertical integration 


\section{Comparing the main components of funding systems}

In this section, we compare for the three countries the role of funding agencies, the types of funding instruments and the categories of beneficiaries, and we measure their share in public research funding. We include also some preliminary information on evolution across time.

It is relevant to consider that we are confronted here with three different countries (see Table 1).

Poland is the largest country in central and eastern Europe, the Czech Republic is a medium-size country with one of the highest levels of economic development, while Estonia is a very small, but until the 2008/9 global financial crisis a rather rapidly developing country. With a GDP per capita of about $80 \%$ of the European (EU-27) average, Estonia and the Czech Republic have the highest levels among CEECs, exceeding also the level of Portugal, while Poland reaches only half of the European level and has the lowest level, just above Bulgaria.

The level of public investment in R\&D and its evolution differ also remarkably. In Estonia and in the Czech Republic, public R\&D expenditures have strongly grown in the last 10 years - both in absolute values and as a percentage of GDP - and are approaching the EU average $(0.63 \%$ of GDP in 2006), while Poland witnessed a stagnation in real terms, respectively a decrease in percentage of GDP and has now one of the lowest levels in the whole EU. In purchasing power parities at prices of 2000 , public funding for research (gross expenditure on R\&D funded by the government) increased from 1998 to 2006 by $150 \%$ in Estonia, by $91 \%$ in the Czech republic, but only by $9 \%$ in Poland (Eurostat database).

Even if in this article we will not try to link directly the structure of public funding systems with outputs, it is interesting to provide some information on this aspect. Results are roughly similar to the analysis of inputs, with the Czech Republic and Estonia sitting just below the EU average and, for some indicators, outperforming some western European countries, and Poland having some of the lowest scores among EU countries together with Bulgaria and Romania.
The Czech Republic and Estonia have about 500 Web of Science publications per million inhabitants per year, which is about two thirds of the EU average and near to level of Spain and Italy, while with fewer than 400 publications per million inhabitants Poland is in the lowest group with levels nearer to the Balkan countries (EC, 2008). Despite its methodological limitations in general (Schibany and Streicher, 2008) and in the measurement of innovation in CEECs, the same picture is provided by the European Innovation Scoreboard, with both Estonia and the Czech Republic belonging to the group of moderate innovators just below the EU average (rank 16 and 18 ) and before most southern European countries, while Poland is in the lowest ranked group (rank 27 in 2008). Both the Czech Republic and Estonia also score significantly better than Poland in the five-year improvement of innovation performance.

\section{Funding agencies}

In an analysis of the role of agencies in public funding, it is interesting to look at two issues: the level of delegation from the national state to autonomous organizations on the one hand; the level of centralization or differentiation of public funding bodies on the other. We distinguish between following categories:

- Research and/or education ministry, usually the main body in charge of research policy; a strong role in funding of the ministry should be probably understood as the lowest level of delegation.

- Other state ministries, still part of the state organization, but with looser linkage to research policy.

- Intermediary agencies, including the research councils, but also other agencies with large autonomy from the state (at least in operational terms).

- International funding agencies, international organizations and the EU framework programs (EU structural funds are included in national funding, since they are usually distributed by a national agency).

- We consider separately the academies of sciences because of their specific organizational setting and role in the research system.

Table 1. Basic data on the involved countries and their research system, 2006

\begin{tabular}{lccc}
\hline & Czech Republic & Estonia & Poland \\
Population in millions & 10.25 & 1.34 & 38.10 \\
GDP (million PPS) & 189,970 & 21,636 & 47,0418 \\
GDP per capita (PPS) & 18,500 & 16,100 & 12,300 \\
GERD (million PPS) & 2,933 & 246 & 2,614 \\
GERD \% GDP & $1.54 \%$ & $1.14 \%$ & $0.56 \%$ \\
GERD financed by GOV (million PPS) & 1,143 & $0.51 \%$ & 1503 \\
GERD financed by GOV as \% GDP & $0.60 \%$ & & $0.32 \%$ \\
\hline
\end{tabular}

Source: Eurostat database 
The picture for the three considered countries is shown in Figure 4.

We are thus facing three different models. In Poland, since 1991 almost the whole budget is concentrated at the research and higher education ministry, thus also funding to academies of sciences institutes is managed directly by the ministry (Jabłecka and Lepori, this issue). Estonia has a mixed structure with a strong education ministry, as well as two largely independent agencies (the Estonian Science Foundation [ESF] and Enterprise Estonia), corresponding to the two ministries in charge of research funding (Ministry of Research and Ministry of Economy; Masso and Ukrainski, this issue). Finally, the Czech Republic has a differentiated structure with the Academy of Sciences keeping a significant and strong role of resort ministries for funding research in their domains.

While in Poland centralization has been very stable in the last 15 years, more significant changes have taken place in the two other countries. In Estonia, the ESF had a dominant role in the first half of the 1990s, but lost importance with the strengthening of the programs directly managed by the education ministry; moreover, a number of research funding programs are nowadays managed by the economics ministry through Enterprise Estonia. We had thus an evolution from a model centralized in the research council towards a more differentiated system. The Czech Republic witnessed a gradual evolution with the educational ministry increasing its role and the other ministries and the Academy of Sciences losing ground, but without a fundamental shift of roles.

\section{Allocation modes}

Concerning allocation modes, we elaborate on the distinction between project funding and institutional funding (see Lepori et al, 2007b) by introducing two further categories: institutional project funding, meaning funding provided to whole research institutions (e.g. universities) for their normal operation, but allocated on the basis of competitive proposals, and centres and networks of excellence, meaning funds provided to support the establishment of new research centres of networks, on a larger scale and longer duration than 'usual' project funding (thus coming nearer to institutional funding). This classifications looks to structural features of the allocation, rather than to issues such as the type of research funded or the specific research themes. Table 2 presents the definitions and the instruments in the considered countries, and Figure 5 shows shares of different allocation modes per country.

In Estonia, project funding covers about three quarters of total funding, while there are very few instruments for institutional funding: three instruments directed to universities and managed by the research ministry, as well as some limited infrastructure funding from the Ministry of Agriculture and the Ministry of Culture. Project funding is more differentiated among agencies including the research ministry, Estonian Science Foundation, Enterprise Estonia and the European Union. Historically, the system switched around 1997-1998 from institutional to project funding with the end of the baseline funding from the Estonian Science Foundation; since 2005 some new instruments for institutional funding of universities have been introduced, but at the same time project funding from European sources has also increased.

Poland displays a share of two thirds for institutional funding and one third for project funding, which is typical of many western European countries (Lepori et al, 2007a); change from the mid-1990s has been limited, except some increase in the share of project funding due to the European framework programs. Almost all national funding is managed

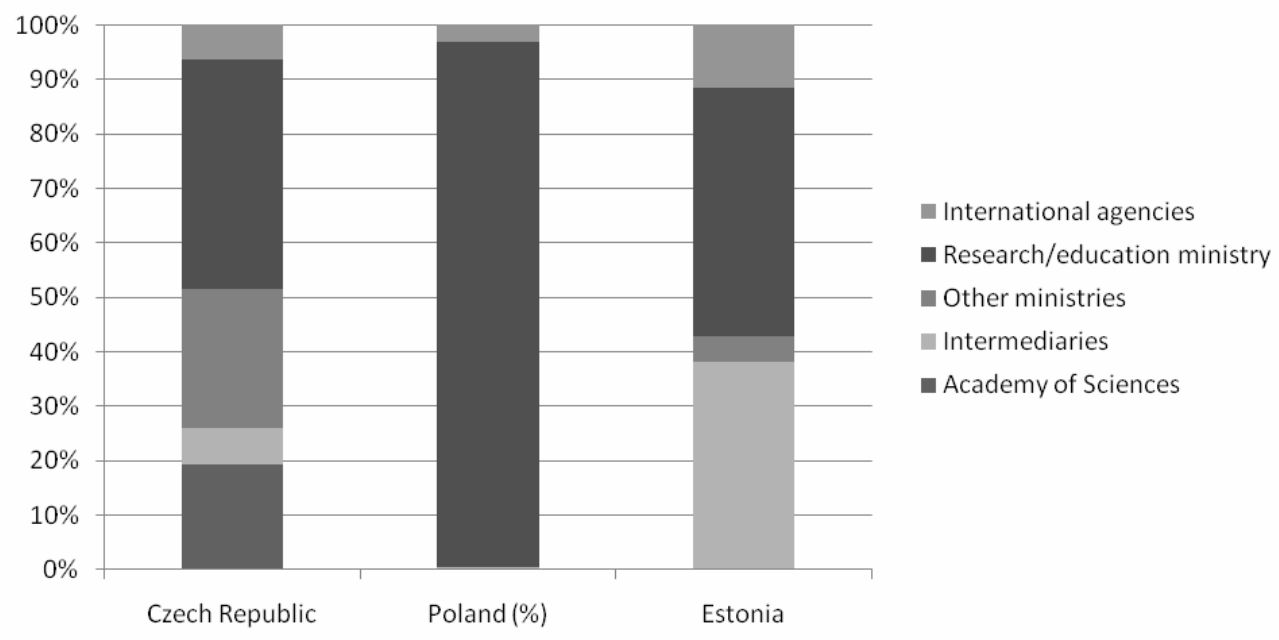

Figure 4. Role of different funding agencies, 2006 (percentages of total public funding)

Notes: Intermediaries: Czech Science Foundation, Polish Foundation for Science, Estonian Science Foundation, Enterprise Estonia and Environmental Investments Centre International agencies: mostly funding from EU Framework Programs, for Poland includes also EU structural funds Estonia: data for 2005 
Table 1. Allocation modes and instruments per country, 2006

\begin{tabular}{|c|c|c|c|c|}
\hline Name & Definition & Czech Republic & Estonia & Poland \\
\hline $\begin{array}{l}\text { Institutional } \\
\text { funding }\end{array}$ & $\begin{array}{l}\text { Funding attributed to whole } \\
\text { research organizations for their } \\
\text { institutional mission and their } \\
\text { long-term existence }\end{array}$ & $\begin{array}{l}\text { - Research plans of } \\
\text { Academy of Sciences } \\
\text { institutes } \\
\text { - Research plans of } \\
\text { governmental institutes } \\
\text { - Specific research funding } \\
\text { of HEls }\end{array}$ & $\begin{array}{l}\text { - MER base financing and } \\
\text { infrastructure costs } \\
\text { - PhD grants programme }\end{array}$ & $\begin{array}{l}\text { - Statutory funding and in- } \\
\text { house research funding } \\
\text { of HEls } \\
\text { - Investments }\end{array}$ \\
\hline $\begin{array}{l}\text { Competitive } \\
\text { institutional } \\
\text { funding }\end{array}$ & $\begin{array}{l}\text { Institutional funding, attributed } \\
\text { through competitive submission } \\
\text { of proposals and with some } \\
\text { possibility of non-renewal of the } \\
\text { grant }\end{array}$ & Research plans of HEls & None & None \\
\hline $\begin{array}{l}\text { Project funding } \\
\text { (national) }\end{array}$ & $\begin{array}{l}\text { Funding attributed for research } \\
\text { activities of limited scope and } \\
\text { duration to individual research } \\
\text { units or researchers }\end{array}$ & $\begin{array}{l}\text { - National Research } \\
\text { Programme and } \\
\text { departmental } \\
\text { programmes } \\
\text { - Czech Science } \\
\text { Foundation grants } \\
\text { - Ministry of Industry and } \\
\text { Trade programs (in fact } \\
\text { departmental } \\
\text { programmes) }\end{array}$ & $\begin{array}{l}\text { - MER targeted financing } \\
\text { - ESF grants } \\
\text { - Enterprise Estonia } \\
\text { programmes } \\
\text { - Others }\end{array}$ & $\begin{array}{l}\text { - Research projects } \\
\text { (bottom-up) } \\
\text { - Goal-oriented projects }\end{array}$ \\
\hline $\begin{array}{l}\text { Project funding } \\
\text { (international) }\end{array}$ & $\begin{array}{l}\text { Project funding attributed by } \\
\text { international agencies and } \\
\text { organizations, including } \\
\text { European Union }\end{array}$ & $\begin{array}{l}\text { EU Framework } \\
\text { Programmes }\end{array}$ & $\begin{array}{l}\text { EU Framework } \\
\text { Programmes }\end{array}$ & $\begin{array}{l}\text { EU Framework } \\
\text { Programmes }\end{array}$ \\
\hline $\begin{array}{l}\text { Networks and } \\
\text { centres of } \\
\text { excellence }\end{array}$ & $\begin{array}{l}\text { Funds devoted to establish } \\
\text { new competences centres and } \\
\text { cooperation networks, however } \\
\text { limited in time and based on } \\
\text { proposal submission }\end{array}$ & $\begin{array}{l}\text { - Research centres } \\
\text { (cooperation networks) } \\
\text { - Centres for basic } \\
\text { research }\end{array}$ & $\begin{array}{l}\text { - Centres of excellence } \\
\text { (COE) programme }\end{array}$ & $\begin{array}{l}\text { - COE } \\
\text { - Technology platforms } \\
\text { - Centres of competence } \\
\text { - Research networks - as } \\
\text { new organizational forms } \\
\text { but funded through } \\
\text { traditional instruments }\end{array}$ \\
\hline
\end{tabular}

by the research ministry, while European framework programs have a significant role.

Finally, the Czech Republic displays the most complex situation. While funding to governmental institutes and Academy of Sciences institutes is allocated through so-called research plans which can be considered as institutional funding, research plans of HEIs - despite having the same name - have quite different allocation mechanisms: namely, they are attributed through competitive submission of proposals and, in the most recent round, some HEIs got their plans refused. This mechanism represents an intermediate between institutional and project funding. Project funding is rather differentiated among ministries managing department programmes on their specific area of competence (as well as a national research programme coordinated by the Ministry of Education, Youth and Sports MEYS). It

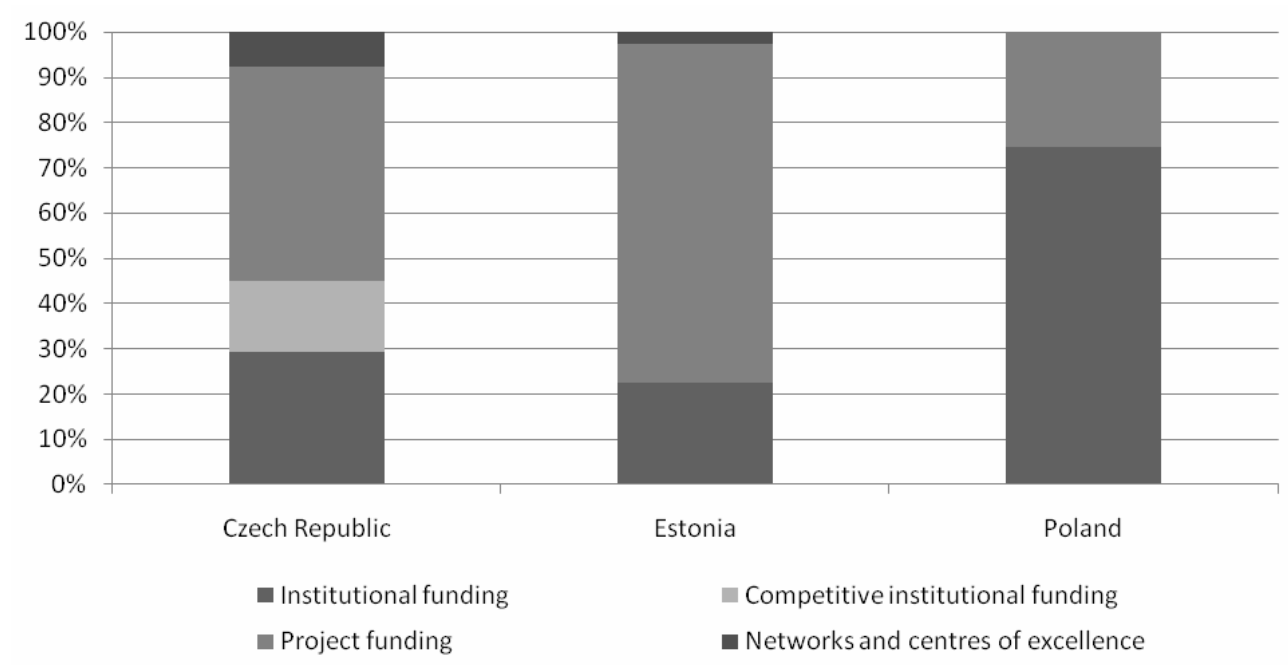

Figure 5. Shares of different allocation modes per country, 2006 
accounted in 2006 for nearly half of the total public funding, and competitive institutional funding (HEI research plans) for a further $16 \%$, while traditional institutional funding (Academy of Sciences and public research organizations) for about $30 \%$. Since the year 2000, there has been a continuous increase in the share of project funding, with a parallel decrease in the share of research plans of research institutes.

\section{Structure of performers}

If we look to the performers, we can distinguish between four main sectors: higher education, the research institutes of the academies of sciences, the remaining institutes in the public sector and, finally, private companies. We are interested in their shares in public funding and its changes across time, but also through which agencies and instruments the different groups are funded (Figure 6).

The Estonian system is dominated by a small number of universities, with the University of Tartu, the University of Tallinn and the Estonian University of Life Sciences receiving 54\% of public funding (including the private sector), while the rest of the system is composed of a large number of smallsize research institutes.

Poland displays a larger system with three sectors: higher education, research institutes, and Academy of Sciences. However, the significance of these divisions is lessened by the fact that allocation of institutional funding is centralized to the ministry using the same rules for the three sectors and that most institutional funding is provided to research units directly (departments in HEIs). Time series display a reinforcement of the HEI sector at the expense of the two other sectors in the 1990s, but stability since then.
The Czech Republic is the only country showing an Academy of Sciences sector with its own funding channels, including an internal project funding agency, alongside a large higher education sector. The share of these two sectors has been rather stable since the year 2001, while other public research institutes continuously decreased since then. The high share of the private sector is largely explained by research institutes that were reorganized ('privatized') from state research organization in first half of the 1990s (both departmental and as part of state industrial companies).These research labs (now mainly registered as limited liability companies or corporations) are still partly oriented towards public research funding and are relatively successful in competition for projects of applied research and in cooperative projects with research centres. This is very different from Poland, where branch R\&D units kept their status, even if many of them had to sell non-research services (such as renting spaces) to survive and thus weakened their traditional role of linking the public research sector and business (Gorzynski et al, 2009).

\section{A summary comparison}

Table 3 provides an overview of the main features of public funding in the three considered countries.

\section{Structural features of CEEC funding systems}

In this section, we use the information from the previous section to understand the overall organization of the funding system in three countries considered.

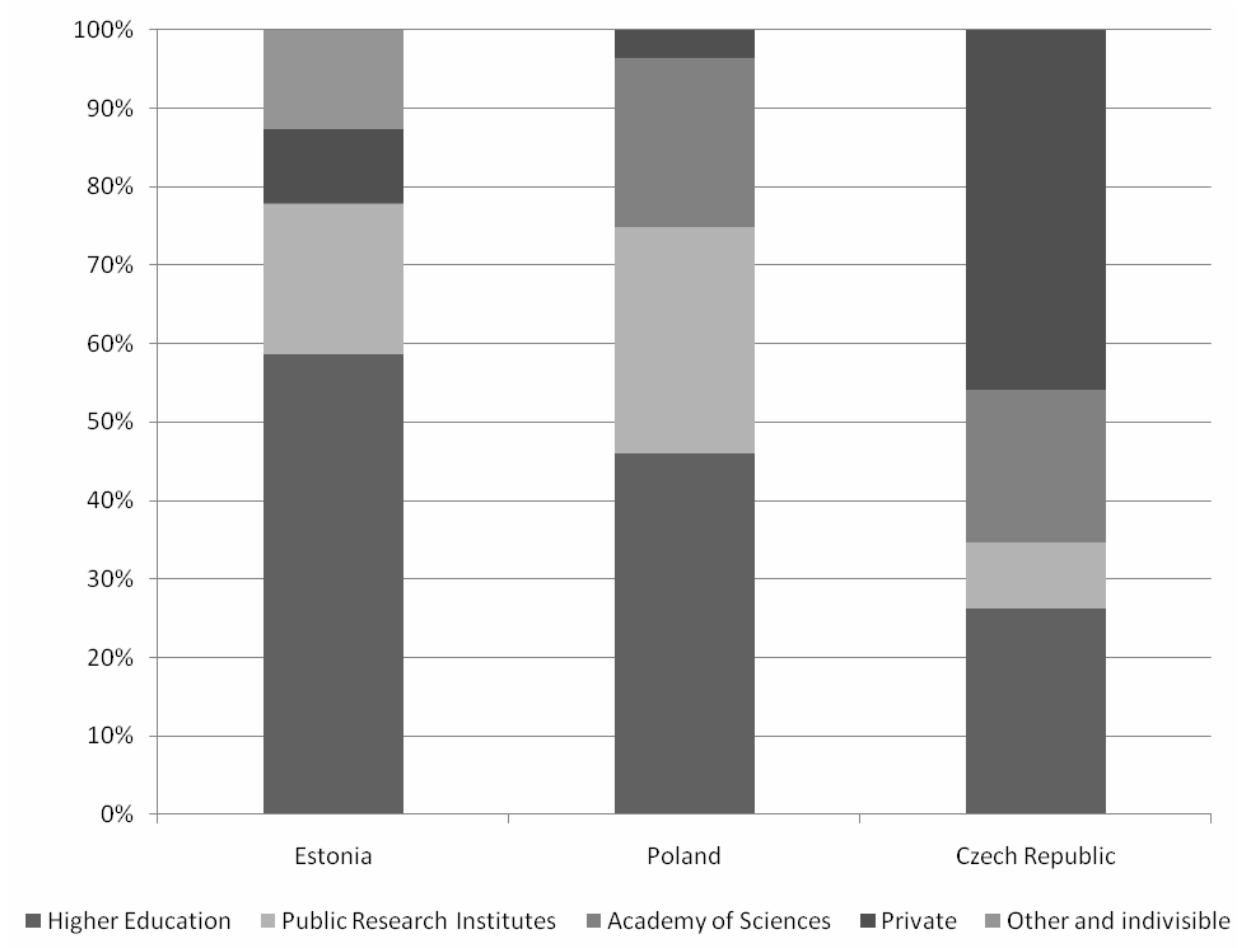

Figure 6. Share of different performers in public research funding, 2005 


\begin{tabular}{|c|c|c|c|}
\hline Country & Funding agencies & Allocation modes & Structure of performers \\
\hline Czech Republic & $\begin{array}{l}\text { The system is highly differentiated, } \\
\text { with an important role for the Ministry } \\
\text { of Education, Youth and Sport, and for } \\
\text { the sectoral ministries; Academy of } \\
\text { Sciences manages a significant } \\
\text { proportion of funding, while } \\
\text { autonomous funding agencies (Czech } \\
\text { Science Foundation) are less relevant }\end{array}$ & $\begin{array}{l}\text { About half of the funding volume is } \\
\text { composed of project funding, half by } \\
\text { institutional funding. Institutional } \\
\text { funding of HEls is attributed through a } \\
\text { competitive procedure rather similar to } \\
\text { project funding, but at the institutional } \\
\text { level. A significant proportion of public } \\
\text { project funding benefits to private } \\
\text { companies }\end{array}$ & $\begin{array}{l}\text { A large } \mathrm{HEI} \text { sector alongside a large } \\
\text { academy of sciences sector; the shares } \\
\text { have been rather stable since } 2001 . \\
\text { Large private research activities }\end{array}$ \\
\hline Estonia & $\begin{array}{l}\text { The most important funding agency } \\
\text { is the Ministry of Education and } \\
\text { Research, alongside the Ministry of } \\
\text { Economy through Estonian Enterprise. } \\
\text { In the 1990s the Estonian Science } \\
\text { Foundation had a dominant role, which } \\
\text { has strongly decreased afterwards }\end{array}$ & $\begin{array}{l}\text { Mostly project funding instruments } \\
\text { with a rather large number of funding } \\
\text { agencies, only a few institutional } \\
\text { funding instruments }\end{array}$ & $\begin{array}{l}\text { HEls play the dominant role and } \\
\text { research capacity is concentrated in } \\
\text { just three universities; a large number } \\
\text { of smaller research units }\end{array}$ \\
\hline Poland & $\begin{array}{l}\text { Since 1991, funding is completely } \\
\text { centralized in the Ministry of Science } \\
\text { and Higher Education which manages } \\
\text { both institutional and project funding }\end{array}$ & $\begin{array}{l}2 / 3 \text { institutional funding and } 1 / 3 \text { project } \\
\text { funding; institutional funding is } \\
\text { allocated to institutional units } \\
\text { (departments in HEls). Substantial } \\
\text { stability since } 2001\end{array}$ & $\begin{array}{l}\text { The } \mathrm{HEI} \text { sector is the largest, but } \\
\text { substantial share of research institutes } \\
\text { and academy of sciences institutes; } \\
\text { strong increase of the role of HEls in } \\
\text { the } 1990 \text { s, but stability since then }\end{array}$ \\
\hline
\end{tabular}

\section{Poland: a system centred on the research ministry}

Poland displays a system where a single player the Ministry of Science and Higher Education (MSHE) - manages almost all public funding, and a single funding instrument — primary statutory funding - is the dominant funding source for all performers in the public sector (see Figure 7).

Moreover, most of the institutional funding is directly allocated to institutional units, departments in HEIs and research institutes in the Academy of Sciences and in the government sector. Project funding plays a significant role as a funding source, but at least in the aggregate, its share is probably too low to be a major force for the structural evolution of the research system.

As a whole, the funding system is characterized by low levels of delegation and by no sectoral divisions, since the basic funding mechanism is the same for all units. At least concerning funding, intermediary structures between the ministry and the institutes level have lost their role, including funding agencies, umbrella organizations such as the Academy of Sciences, but also the directions of the universities.

With the reform of 1991, decision-making power was originally attributed to a committee composed of scientists themselves with little intervention from the public administration; this changed after 2000 with the creation of the Ministry of Science and Higher Education, while first steps towards more delegation of funding competences to autonomous agencies were take after 2004 (Jablecka and Lepori, this issue). Thus, Poland basically adopted the vertically integrated model at the level of the whole country.

In evolutionary terms, structural change from the soviet period has been rather limited, with the ministry replacing the Academy of Science in the central role of allocating body, and co-opting the same scientific elites in the decision-making process. The reform of 1991, with the centralization of funding in the ministry, had the effect of largely transferring the old system of allocation to the new political regime, making further reforms difficult.

\section{Estonia: limited competition between few players}

The Estonian system displays a structure characterized by the variety of funding agencies and sources, but a limited number of relevant performers (Figure 8 ). Differentiation in the funding agencies took place from the 1990s - when the Estonian Science Foundation had a dominant role - with the strengthening of the role of the Ministry of Education and Research, the creation of Enterprise Estonia and the emergence of European Union framework programs as a major funding source.

At the same time, at the performer's level, the system underwent a concentration process with the integration of the research institutes of the Academy of Sciences in the universities; this process is probably also related to the small size of the research system (public research funding amounted to $€ 65$ million in 2005, including EU funds). Nowadays, the three largest players in the public research system - University of Tartu, Tallin University of Technology and the Estonian University of Life Science - account for over $70 \%$ of the total funding from the most important national instruments, and $100 \%$ of funding from the centres of excellence programme. This pattern is consistent across instruments - with similar shares of the main players for most instruments - and increases also with time (Masso and Ukrainski, this issue).

We find here the opposite situation to that in Poland: there is strong delegation and limited coordination at the level of the funding agencies, but three 


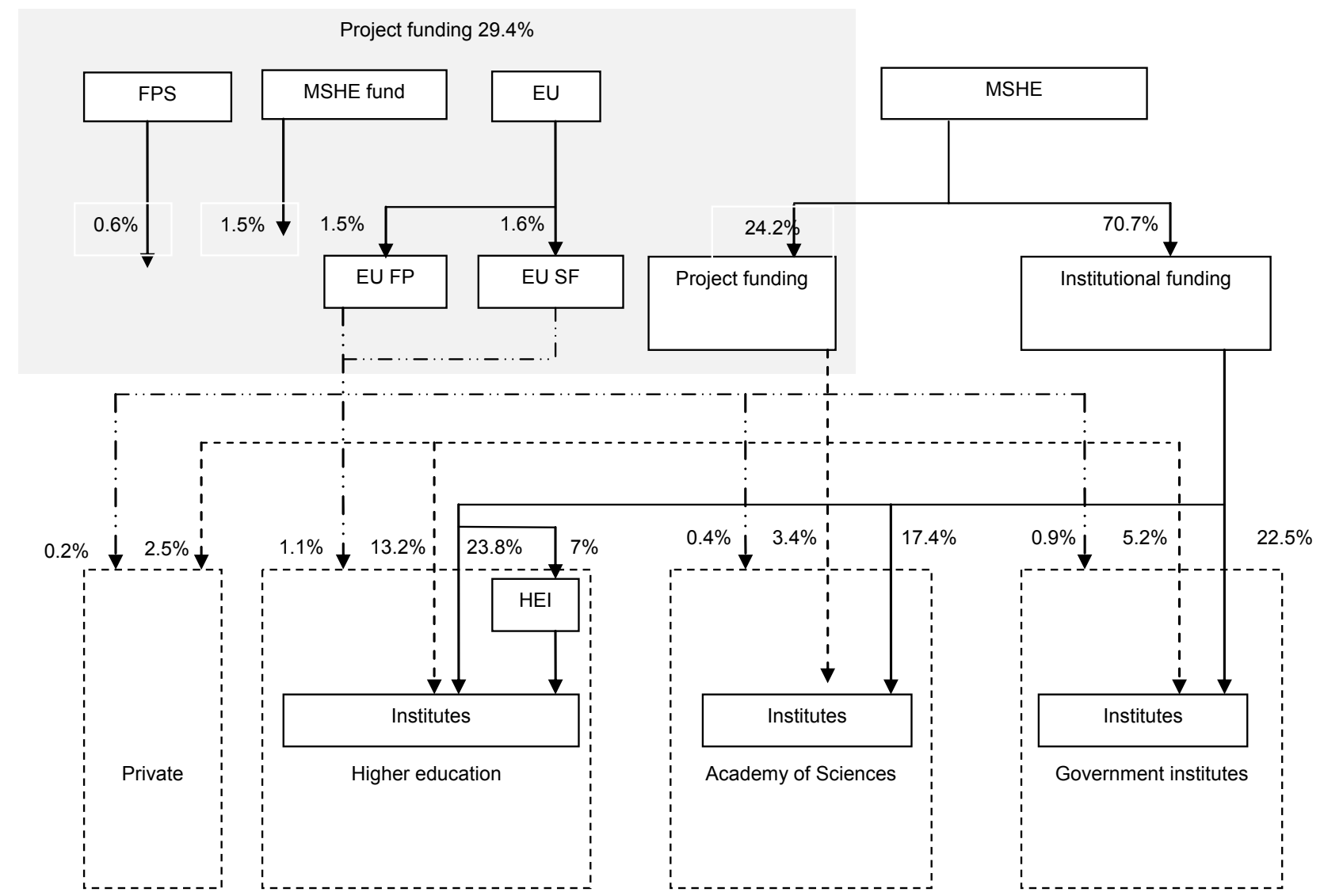

Figure 7. Poland: structure of the public funding system, 2006

Note: For MSHE fund and Foundation for Polish Science there are no data on beneficiaries

performers dominate the research system and consistently get similar shares from each agency. In this case, one can assume that the performers largely drive the allocation decisions of funding agencies. In so small a system, the prevalence of project funding and the lack of central steering lead to strong concentration because of cumulative effects, reducing the diversity of performers and, in the end, also the level of competition. Consequently, one might fear adverse effects on the innovation capacity of the system in the long run.

\section{Czech Republic}

The Czech Republic displays the most complex system, where sector divisions between Academy of Science, departmental research centres and HEIs are strong also concerning funding (Figure 9).

Thus, the Academy of Sciences sector is characterized by its specific institutional funding mechanism, but at the same time is able to get a significant share of project funding, while other public research institutes are financed through their responsible ministry, and get low resources from project funding. Finally, HEIs receive $85 \%$ of their resources through competitive allocation mechanisms, both quasiinstitutional and project.

There are two further characteristics of the Czech system that have to be mentioned. First, the role of independent intermediary bodies (CSF) in project funding is negligible and most project funding is managed directly from ministries (Ministry of Education and Ministry of Industry being the most important). The relevant exception is the Academy of Sciences, which has an highly autonomous position (organizational and financial), but internal allocation is largely institutional, while funding from the internal science foundation represent a small share of the total volume.

The second characteristic is the significant role of (legally) private research labs in the Czech public research funding system. This sector consists partly of former state research institutes and research departments of state-owned industrial companies that were restructured in first half of the 1990s and retain a significant role in applied research funded by both public and private sources.

Thus, the organization of funding is characterized by a strong fragmentation of the whole system, with each performing sector having preferred linkages with its own main funder and high diversity of allocation criteria. While this could be seen as a way of keeping diversity of performers and functions in a rather small-scale system, this could limit the level of competition to actors inside the same sector (and even more concerning departmental institutes). The rather high share of project funding is likely to promote some intersectoral competition, but one could raise some questions if the lack of independent agencies and the fragmentation into a large number of departmental programmes led to competition or to the creation of small-scale circles of (repeating) customers for each specific programme. 


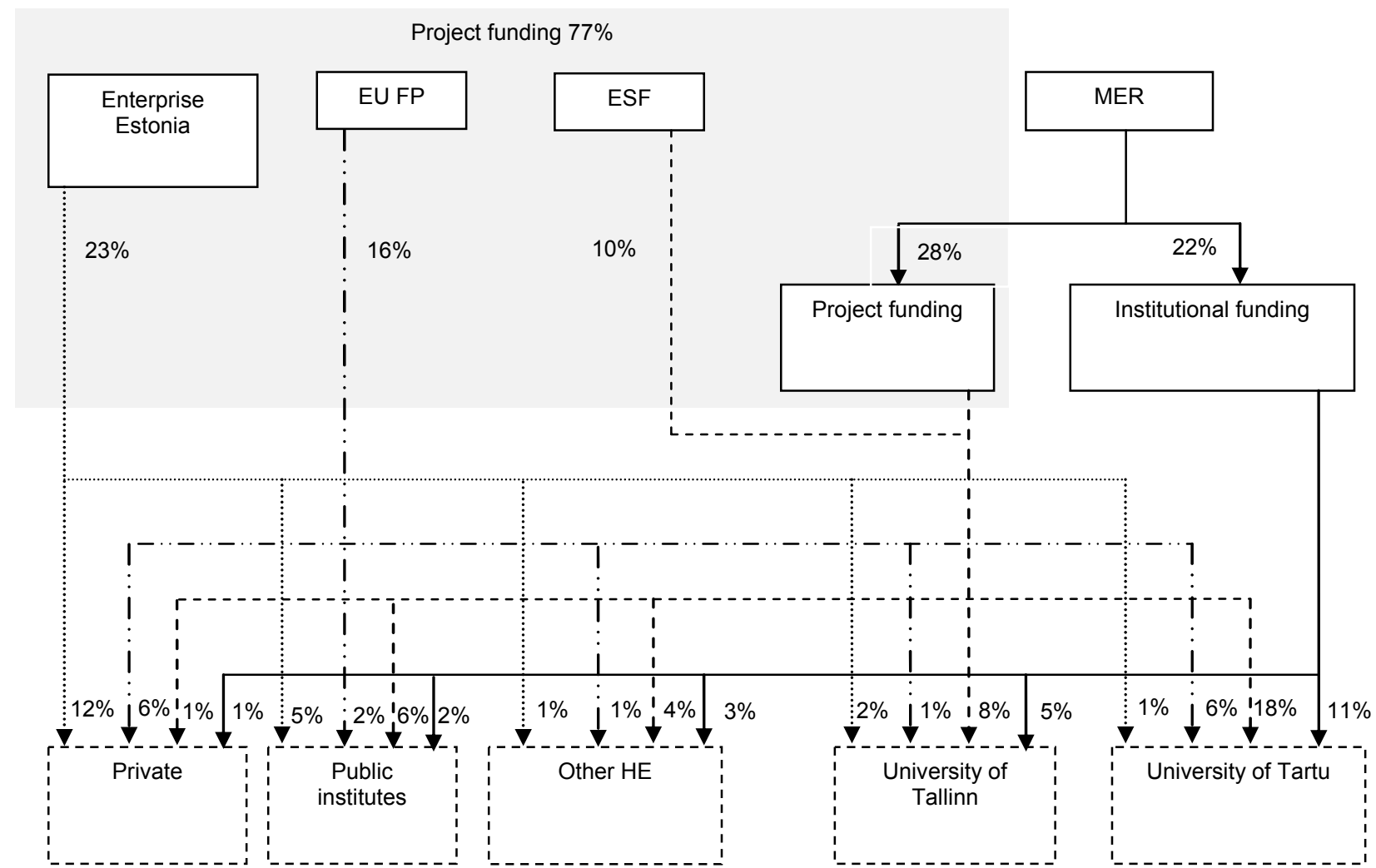

Figure 8. Estonia: structure of the public funding system, 2005

Note: $\quad$ Only the main funding instruments have been considered that in 2005 accounted for $90.2 \%$ of the total funding. The numbers at beneficiaries need not to add up to $100 \%$ because of rounding. For some of the Enterprise Estonia funding (about $2 \%$ of research funding) the sums were indivisible across beneficiaries

\section{Conclusions}

From the previous analysis, it is apparent that the three countries considered display different organizational forms of research funding. This emerges not only by comparing the aggregate indicators, such as the level of public funding, the share of project funding and the role of different performers, but especially by looking at how the relationships between state, funding agencies and performers are organized.

Thus, the Polish system displays a very high level of centralization, with the ministry managing directly almost all national funding and with intermediary bodies and research organizations having a very limited role in allocating resources to research groups. Funding streams are differentiated by their allocation criteria (e.g. between institutional and project funding), but not concerning the organizational setting (e.g. having different agencies in charge of project funding). Institutional funding to research groups is substantially larger than project funding (70\% against $30 \%$ ).

The Estonian model displays the opposite pattern with almost complete delegation of funding to (largely uncoordinated) agencies financing all performers (at least in principle), but with a very strong concentration at the level of performers, with only three large players and one generalist university (Tartu) covering most of research areas. The share of project funding ( $78 \%$ of public funding) is very high in the European context.
Finally, the Czech Republic shows a fragmented structure, with a large and essentially autonomous Academy of Sciences sector inherited from the Communist regime alongside a large higher education sector, subject to a much more competitive allocation of funding (with competitive research plans at the level of whole universities). The share of project funding is fairly large (48\%), but there is strong fragmentation in departmental programmes related to specific policy areas, rather than delegation to specialized agencies.

In a way, it seems these countries exemplify three possible organizational structures of public funding: Poland is a good example of the vertically integrated system (managed by scientists' representatives) which characterized France in the old centralized system based on the CNRS and other large PROs (Mustar and Larédo, 2002), while the Estonian system resembles closely the US model where research funding is based on project funding agencies. Finally, the Czech system is not too far from the situation in a number of western European countries such as Germany, Spain and Italy, characterized by two thirds of general funding, mostly to universities, and one third of project funding and the coexistence of universities and large PROs competing for projects and receiving institutional funding through distinct channels (Lepori et al, 2007a). It would take a broader comparative analysis to understand if these are the only basic organizational forms of public funding and to look deeper to national variants (e.g. 


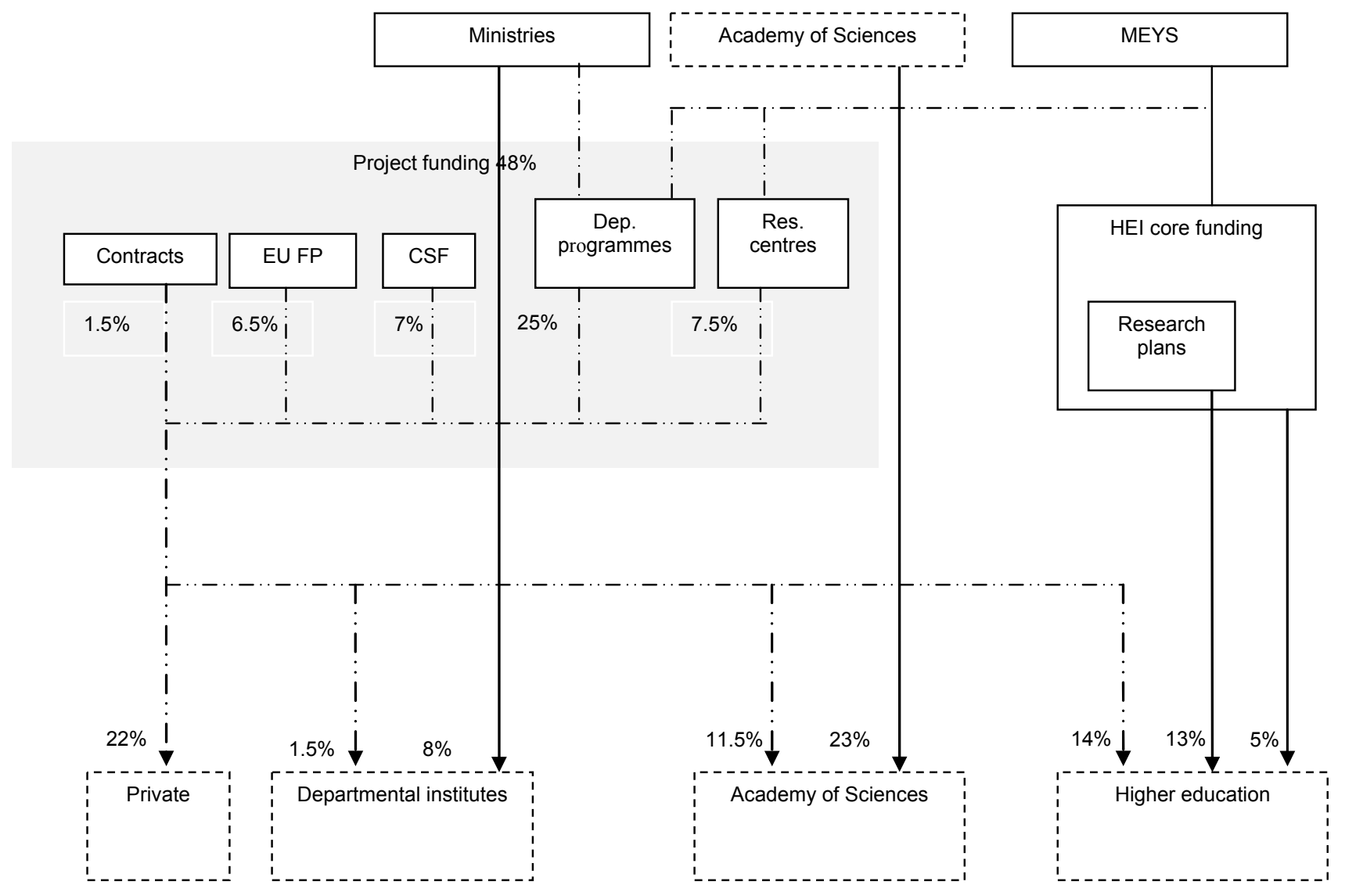

Figure 9. Czech Republic: structure of the public funding system, 2005

in the organization of project funding agencies, as shown in the case of western European countries).

The relevant question is why in the transition from a broadly similar Communist system - characterized by strong centralization and the central role of the Academy of Science - these countries designed three very different systems, with differences which are larger than between continental European countries and seem to span the whole range of organizational forms of public research systems. While this would require a deeper historical analysis, the case study on Poland provides some suggestions (Jabłecka and Lepori, this issue); namely, it shows that the breakdown of the Communist regime was so rapid and time to design new structures so short that strongly contextual factors - such as some experiences with western systems, the personality and individual beliefs of the involved people and preexisting power relations - played a central role in shaping the reforms. Under these conditions, one can expect that, first, different models and ideas are taken in each country and, second, that their transfer can lead to very different interpretations given the limited information and experience available (as demonstrated by the reference to the research council model in the Polish case).

Moreover, exactly because of the short time available, structures inherited from the past had a lasting effect in shaping the new system, even if the official discourse had to represent it as a dramatic change. Thus, by and large Poland reproduced at the ministerial level the old centralized system of the communist Academy of Sciences, while in Estonia the need to find an organizational setting for the Academy of Sciences institutes - after their separation from the USSR Academy of Science - and to create critical mass in a very small-scale system was addressed by merging them into the existing higher education institutions, thus leading to the concentration of performers which is the main structural feature of today's system. From an institutional perspective, it is not surprising that disruptions of organizational fields due to external shocks - such as the breakdown of the Communist regimes - led to experimentation with different solutions bound to contextual factors.

What is however relevant is the stability of the emerging trajectories in the three considered countries. Major structural changes took place mostly in the 1990s, while in the last decade most changes have been evolutionary, such as shifts in the relative importance of sectors (Czech Republic) and some adaptations in structures and funding instruments (Poland). Of course, learning from other countries, imitation and normative pressure, for example from the European Commission and the OECD, can take place in this phase, but their effects seem to be largely incremental and limited by the structures already in place. This confirms the widespread belief in theories of institutional change that marginal differences in performance between (national) systems are not sufficient to trigger large structural changes, without external shocks disrupting the system already in place. 
A final remark concerns the impact of these models on the ability of the state centrally to steer the system, on the delegation pattern, as well on the capacity of promoting diversity and innovation in the research system versus the efficiency in the allocation of resources. Namely, based on the existing literature, one can argue that well-functioning funding systems have to find a balance between largely contrasting requirements: first, to allow some steering of the research system towards broader policy goals versus leaving a sufficient degree of autonomy to scientists and research groups (Braun, 2003); second, to allocate money to the best performing researchers versus keeping sufficient diversity in the research system to let new actors and research ideas emerge despite cumulative effects.

The three considered countries display some potential pitfalls in this respect, as well as the need to take into account local conditions in implementing funding systems. Thus, the Polish case shows that centralization does not necessarily promote steering capacity and efficiency, if the required competences and information infrastructure is not available. On the contrary it led to stability and inertia at least if judged at the aggregated level: not only there have been rather few changes since 1991, but also the Polish system performs rather badly both concerning the ability to mobilize resources and the level of outputs for academic research. Delegation to funding agencies and competition on project funding alongside the very successful US model - would seem an attractive solution in this respect.

However, in the Estonian context the system is so small that cumulative effects prevail and a few performers end up dominating the system (Masso and Ukrainski, this issue). While this might be very efficient in the short run, one could fear that it might reduce innovativeness and responsiveness to new needs in the long run. Moreover, one might enquire to what extent funding agencies are able to drive the development of a research system when for each domain there are just a few potential applicants. Ironically, a more centralized steering approach would seem more adequate in Estonia than in Poland given the different size of the system.

In the Czech case, the concentration of core funding in the research ministry and the Academy of Sciences creates strong principals for their sector and thus allows for more active steering using the research plans instrument. However, sectoral fragmentation in a rather small system entails the risk that stable relationships between principals and agents largely determine the outcome of the allocation process, despite formally competitive criteria, and thus reduce competition and efficiency (especially for departmental programmes which target very specific research domains).

In a nutshell, there is no best organization of public funding of research; each model entails its own advantages and disadvantages, as well as tradeoffs between different goals (e.g. performance vs. innovation); further, the functionality of the different models largely depends on their embeddedness in specific national contexts and thus what works in one country could not perform as well in another country. All this opens further interesting avenues both for scholarly research and for the development of public policies.

\section{References}

Amable, B 2000. Institutional complementarities and the diversity of social systems of innovation and production. Review of International Political Economy, 7, 645-687.

Bonaccorsi, A 2007. Explaining poor performance of European science: institutions versus policies. Science and Public Policy, 34(5), June, 303-316.

Braun, D 1998. The role of funding agencies in the cognitive development of science. Research Policy, 27(8), 807-821.

Braun, D 2003. Lasting tensions in research policy making - a delegation problem. Science and Public Policy, 30(5), 309-321.

Braun, D, M Benninghoff, R Ramuz and J-P Leresche 2003. Learning Capacities in Public-funded Research Systems. Research report, Lausanne.

EC, European Commission 2008. Science, Technology and Competitiveness Key Figures Report 2008/2009. Brussels: EC.

Gorzynski, M and M Jakubiak 2008. ERAWATCH Country Report 2008. Poland. Brussels.

Guston, D 2000. Between Politics and Science: the Integrity and Productivity of Research. Cambridge: Cambridge University Press.

Jabłecka, J and B Lepori 2009. Between historical heritage and policy learning: the reform of the public research funding system in Poland 1989-2007, Science and Public Policy, this issue.

Jongbloed, B 2008. Creating public-private dynamics in higher education funding: a discussion of three options. In PublicPrivate Dynamics in Higher Education, eds. J Enders and B Jongbloed. Bielefeld: Transcript.

Larédo, P 2008. Peer reviewing: what differences do organizations make? EGOS/WZB workshop 'Peer Review Reviewed', Berlin, 24-25 April 2008.

Laudel, G 2006. The quality myth: promoting and hindering conditions for acquiring research funds. Higher Education, 52, 375-403.

Lemola, T 2002. Convergence of national science and technology policies: the case of Finland. Research Policy, 31(8-9), 1481-1490.

Lepori, B, P van den Besselaar, M Dinges, B Potì, E Reale, S Slipersaeter, J Thèves and $B$ van der Meulen 2007a. Comparing the evolution of national research policies: what patterns of change? Science and Public Policy, 34(6), July, 372-388.

Lepori, B, P van den Besselaar, M Dinges, B van der Meulen, B Potì, E Reale, S Slipersaeter and J Thèves 2007b. Indicators for comparative analysis of public project funding. concepts, implementation and evaluation, Research Evaluation, 16(4), December, 243-255.

Masso, J and K Ukrainski 2009. Competition for public project funding in a small research system: the case of Estonia. Science and Public Policy, this issue.

Meske, W ed. 2004. From System Transformation to European Integration. Science and Technology in Central and Eastern Europe at the Beginning of the 21st Century. Reihe: Soziologie: Forschung und Wissenschaft, Bd. 7, 2004, $496 \mathrm{~S}$.

Mustar, $P$ and $P$ Larédo 2002. Innovation and research policy in France (1980-2000) or the disappearance of the Colbertist State. Research Policy, 31(1), 55-72.

Poti, B and E Reale 2007. Changing allocation models for public research funding: an empirical exploration based on project funding data. Science and Public Policy, 34(6), July, 417-430.

Radosevic, S 2005. Are systems of innovation in Central and Eastern Europe inefficient? Paper presented at the DRUID 10th anniversary conference, Copenhagen, June 2005.

Radosevic, S and L Auriol 1998. Patterns of restructuring in research, development and innovation activities in Central and 
Eastern European countries: analysis based on S\&T indicators, Research Policy, 28(4), 1999, 351-376.

Sanz-Menéndez, $L$ and $L$ Cruz-Castro 2003. Coping with environmental pressures: public research organisations responses to funding crises. Research Policy, 32, 1293-1308.

Schibany, $A$ and $G$ Streicher 2008. The European Innovation Scoreboard: drowning by numbers? Science and Public Policy, 35(10), December, 717-732.

Senker, J et al 1999. European Comparison of Public Sector Research Systems. Brighton.

Sima, K 2008. Czech Republic country report. Research funding systems in Central and Eastern European Countries, PRIMECEEC report.

Slipersaeter, S, B Lepori and M Dinges 2007. Between policy and science: research councils' responsiveness in Austria, Norway and Switzerland. Science and Public Policy, 34(6), July, $401-416$.
Stephan, J 2002. The productivity gap between East and West Europe: what role for sectoral structures during integration? Acta Oeconomica, 52, 289-305.

Thèves, J, B Lepori and $P$ Larédo 2007. Changing patterns of public research funding in France. Science and Public Policy, 34(6), July, 389-399.

Van der Meulen, B 2003. New role and strategies of a research council: intermediation of the principal-agent relationship. Science and Public Policy, 30(5), October, 323-336.

Viner, N, R Green and P Powell 2006. Segmenting academics: resource targeting of research grants. Science and Public Policy, 33(3), 166-178.

White, H 2002. Markets from Networks: Socioeconomic Models of Production. Princeton University Press.

Whitley, R 2003. Competition and pluralism in the public sciences: the impact of institutional frameworks on the organisation of academic science. Research Policy, 32, 1015-1029. 